\title{
Should a higher-order metaphysician believe in properties?
}

\author{
David Liggins ${ }^{1}$ (1)
}

Received: 27 August 2020 / Accepted: 24 May 2021 / Published online: 4 June 2021

(C) The Author(s) 2021

\begin{abstract}
In this paper I take second order-quantification to be a sui generis form of quantification, irreducible to first-order quantification, and I examine the implications of doing so for the debate over the existence of properties. Nicholas K. Jones has argued that adding sui generis second-order quantification to our ideology is enough to establish that properties exist. I argue that Jones does not settle the question of whether there are properties because-like other ontological questions-it is firstorder. Then I examine three of the main arguments for the existence of properties. I conclude that sui generis second-order quantification defeats the "one over many" argument and that, coupled with second-order predication, it also defeats the reference and quantification arguments.
\end{abstract}

Keywords Higher-order metaphysics · Properties · Higher-order quantification · Second-order quantification

\section{Non-substitutional, non-nominal quantification}

Nominal quantification is quantification into the syntactic position held by a singular term. It appears in the English sentence 'Something is red' and the formula ' $\exists x$ F $x$ ' of predicate calculus. All other quantification is non-nominal. For example, the formula ' $\exists X X \mathrm{a}$ ' involves quantification into predicate position (second-order quantification) rather than nominal quantification.

How should formulae such as ' $\exists X X \mathrm{a}$ ' be interpreted? We might read them objectually. For example, we could read these formulae as disguised talk of properties and instantiation: then ' $\exists X X \mathrm{a}$ ' would mean 'There is a property had by $a$ '. Another objectual reading takes them to concern sets: on this reading, ' $\exists X X \mathrm{X}$ ' would mean

David Liggins

david.liggins@manchester.ac.uk

http://www.manchester.ac.uk/research/david.liggins

1 Department of Philosophy, School of Social Sciences, The University of Manchester, Oxford Road, Manchester M13 9PL, UK 
'There is a set containing $a$ '. Alternatively, we might read ' $\exists X X \mathrm{a}$ ' as 'There is a linguistic expression such that substituting it into "__a" yields a truth'. (I will call this reading of the quantifier 'substitutional quantification'.) All these interpretations take second-order quantification to be reducible to first-order quantification (over properties, sets, or linguistic expressions respectively). In this paper, I will explore the implications of taking second-order quantification to be sui generis, irreducible to first-order quantification. In particular, I will ask what difference adding this piece of ideology makes to the debate within metaphysics over the existence of properties.

Nicholas K. Jones (2018) has already given an answer to that question. Jones argues that introducing irreducible second-order quantification reshapes the debate, and indeed settles it in favour of the existence of properties. (Jones's paper in fact covers properties and relations, but for simplicity I will just consider here what he says about properties. Nothing essential is thereby lost.) I agree that it reshapes the debate, but I do not agree that it allows us to establish the existence of properties. As I see it, introducing this sort of quantification weakens the case for belief in properties. In Sect. 2 I will set out Jones's arguments and present some objections to them. Then in the remainder of the paper I will argue that bringing in irreducible second-order quantification defeats three of the principal arguments for the existence of properties.

Some will hold that this project is pointless because the sort of quantification I am discussing is unintelligible. What could ' $\exists X X \mathrm{X}$ ' mean if interpreted neither objectually nor substitutionally? It is not my purpose to deal with this challenge here, but I will make a couple of remarks to signal my attitude towards it. First, the claim that all quantification is either objectual or substitutional is a Quinean dogma which has never been established by argument (Williams, 1976, p. 15). Second, I think I know what ' $\exists X X \mathrm{a}$ ' means on the intended reading; the fact that I cannot manifest that knowledge by providing a synonymous English sentence casts no doubt on that, since English might lack the resources to express some things that higher-order predicate calculus can (cf. Williamson, 2003, p. 459). In Sect. 3.2 I will also assume the intelligibility of another piece of higher-order apparatus, namely, predicates of predicates. So this paper is not just about the implications of adding sui generis second-order quantification to our ideology, but of adding higher-order resources more generally.

Some recent discussions of the metaphysics of properties are weakened by neglecting the possibility that higher-order resources might be sui generis. For instance, Howard Peacock (2009) claims that certain forms of anti-realism about properties are 'defeated' (184) by an inability to account for qualitative sameness and difference. Responding to the idea that second-order quantification could help here, Peacock writes: 'the nominalist merely replaces the challenge posed by firstorder quantification over types with the challenge posed by second-order quantification over whatever it is that predicates refer to' (208). But Prior (1971) and others had already suggested that the objectual reading of second-order quantification is not the only one. "The question what [a predicate variable] "stands for" ... i.e. what would be designated by an expression of the sort for which it keeps a place, is senseless, since the sort of expression for which it keeps a place is one which just hasn't the job of designating objects' (Prior, 1971, p. 35). So Peacock's declaration 
of victory is premature. In the same vein as Peacock, Jago (2018, p. 63) argues that second-order quantification does not help to avoid commitment to properties, but in doing so he assumes that there are things that second-order quantifiers range over, thereby weakening his argument.

My inquiry is part of a wider movement in philosophy to explore the implications for metaphysics of adding sui generis higher-order resources to our ideology: as well as Jones (2018), see, for example, Prior (1971), Boolos (1984), Rayo and Yablo (2001), Williamson (2013), Krämer (2014), Cameron (2019), and Skiba (forthcoming). The movement has been called 'higher-order metaphysics'-hence my title.

\section{Jones's second-order realism}

\subsection{Jones's case for second-order realism}

Jones (2018, pp. 809-811) defines two sorts of realism about properties. First-order realism is the thesis that for a certain range of substitutions for ' $\Phi$ ', the instances of this schema are true:

Exist 1: $\square \forall x(\Phi x \rightarrow \exists y(\mathrm{I} x y \wedge \square \forall z(\mathrm{I} z y \rightarrow \Phi z)))$.

where 'I' regiments the predicate 'instantiates' and ' $\Phi$ ' holds a place for a predicate. An approximate English rendering of an instance of Exist 1 is:

(1) It is necessary that: there is something each red thing instantiates, and necessarily, only red things instantiate it.

Exist 1 contains only first-order quantification: the quantifiers in Exist 1 bind variables in singular term position. The substitution range for ' $\Phi$ ' determines how abundant the realism is: a wider range leads to a more abundant theory.

Second-order realism is the thesis that for a certain range of substitutions for ' $\Phi$ ', the instances of this schema are true:

Exist 2: $\square \forall x(\Phi x \rightarrow \exists Y(Y x \wedge \square \forall z(Y z \rightarrow \Phi z)))$.

where again ' $\Phi$ ' holds a place for a predicate. (Jones's original Exist 1 and Exist 2 have strings of variables in place of ' $x$ '; as I said, I am just dealing with the monadic case here.)

Exist 2 uses a second-order quantifier, ' $\exists Y$ '. Jones stipulates that this is to be understood as sui generis, not as first-order quantification in disguise. So Exist 2 is not a mere notational variant of Exist 1. An English rendering of an instance of Exist 2 is:

(2) It is necessary that, for all $x$, if $x$ is blue, then there is a way for things to be such that (i) $x$ is that way; and (ii) necessarily, everything that is that way is blue.

This rendering is approximate, since it simulates the second-order quantifier ' $\exists Y$ ' using first-order quantification over ways. That caveat made, it is worth noting 
that (2) is enormously plausible. Surely there is a way to be that necessarily everything blue is-namely, being blue.

Unlike familiar versions of realism, second-order realism makes no use of any notion of instantiation.

For Jones, establishing either first-order realism or second-order realism about properties is enough to show that properties exist. Moreover, he gives an argument for second-order realism. It relies on existential generalization into predicate position, which is the following rule:

From A, infer $\exists Y(Y \mathrm{~A}[Y / \Phi])$.

where ' $\mathrm{A}[Y / \Phi]$ ' is 'A' with (zero or more) occurrences of the predicate $\Phi$ replaced with ' $Y$ '. ('A' must not contain ' $Y$ ' to begin with.) This is widely accepted as a valid rule of second-order logic, parallel to existential generalisation within firstorder logic (see e.g. Hale, 2013, p. 181). Where ' $F$ ' is an arbitrary predicate, it is-as Jones (2018, p. 812) puts it—'uncontroversially true' that:

(3) $\square \forall x(\mathrm{~F} x \rightarrow(\mathrm{F} x \wedge \square \forall z(\mathrm{~F} z \rightarrow \mathrm{F} z)))$.

Starting from (3), existential generalization into predicate position and standard logical moves deliver the instances of Exist 2. "[O]nce the intelligibility of second-order quantification and validity of [existential generalization into predicate position] are admitted, the characteristic existential claims of second-order realism follow from uncontroversial truths' (Jones, 2018, p. 812). For this reason, Jones thinks that second-order realism ought to be 'relatively uncontroversial' (Jones, 2018, p. 812).

Jones goes on to argue that second-order realism resolves long-standing questions about properties. Philosophers have long debated whether properties are located in space, and whether they should be thought of as universals or tropes. Jones (2018, pp. 817-830) argues that second-order realism dissolves the question of whether properties have a location, and resolves the second debate in favour of universals.

These arguments are not the focus of my response to Jones, but it will be helpful to sketch Jones's case for thinking that second-order realism dissolves the location question. From a first-order perspective, we ask the question "Are properties located?" using a binary first-order predicate such as 'is located at'. One of its positions is open to names for locations, the other for names for properties; then we can use it to ask (for instance) "Is electronhood located at Sydney?". From a higher-order perspective, asking the same question requires a location predicate one of whose argument positions is open to names for locations, the other to predicates. Symbolizing the location predicate by ' $L$ ', we can then ask questions such as "Is it the case that L(is an electron, Sydney)?". Jones (2018, p. 821 ) argues that such a predicate 'does no work, resolves no puzzles, and explains nothing' and that the higher-order realist can legitimately reject its coherence, thereby dissolving the debate over the location of properties.

That is how Jones argues that a higher-order perspective on the properties debate resolves it in favour of realism about properties. 
Philosophers often argue for the existence of properties on the grounds that they are required as the referents of (putative) singular terms such as 'humility' (see Sect. 3.2). It seems that, if sound, this would establish a version of first-order realism about properties; if so, it would reopen the location debate. Jones (2018, p. 814) does not offer to tackle this argument. He emphasizes that he offers second-order realism in an 'exploratory spirit' (2018, p. 809) and does not claim that it can answer all the motivations for positing properties.

Jones's position resembles Amie L. Thomasson's. For Thomasson, the ontological question of whether there are properties can be quickly settled: if we pick the right house, 'The house is red' is uncontroversially true; the sentence 'There is a property, redness, that the house has' follows from it by a 'trivial inference'; and so the question of whether there are properties is answered (Thomasson, 2015, p. 157). Jones could echo Thomasson as follows: 'If we pick the right house, "The house is red" is true. Formalize this as "Rh". Then we can deduce: $\exists Y(Y \mathrm{~h} \wedge \forall z(Y z \rightarrow \mathrm{R} z))$. And that establishes the existence of properties.' Critics have objected that Thomasson's allegedly 'trivial' inference might not be truth-preserving (Button, 2020; Eklund, 2016). Where Thomasson draws on conceptual connections, Jones in effect draws on standard logical rules_-rules which are widely agreed to be truth-preserving. Jones's argument is therefore stronger in this important respect.

\subsection{Has Jones changed the subject?}

Having summarized Jones's contribution to the properties debate, I now make some critical comments on it. (For an alternative response to Jones, see Skiba forthcoming.)

First, a methodological point. It is notable that Jones concentrates on principles that are modally very strong. Instances of Exist $\mathbf{2}$ are claims that something is necessary (and that thing itself involves necessity). I take it that the debate over properties is primarily over whether they exist; the modal status of their existence (or non-existence) is a further question. I therefore recommend that we concentrate on a weakened, de-modalized version of Exist 2, namely:

Exist $2 *: \forall x(\Phi x \rightarrow \exists Y(Y x \wedge \forall z(Y z \rightarrow \Phi z)))$.

Second-order realism* is the thesis that for a certain range of substitutions for ' $\Phi$ ', the instances of Exist $2 *$ are true. Jones ought to believe that establishing secondorder realism* would establish the existence of properties.

I accept that Jones has established second-order realism*. My main criticism is that this doctrine does not answer the question 'Do properties exist?'. Ontological debate about properties (and other disputed entities) is very largely conducted using first-order language such as 'exist'. For example, we use such language when we introduce the subject-matter of ontology by saying that ontology aims to answer questions such as 'Do numbers exist?'. Ontologists have spoken this way for a long time. We may therefore reasonably worry that Jones has changed the subject: first-order questions such as 'Are there properties?' and 'Does redness exist?' seek first-order answers. Jones agrees that English 'exists' is 
non-second-order (2018, p. 816): strings of words such as 'Is an electron exists' are not grammatical English sentences. I am inclined to think that this settles the question 'Do second-order sentences express existence claims?' in the negative. But Jones evidently does not think so.

Jones engages with this objection in the following passage:

First- and second-order quantifiers both express kinds of generalisation. The question is whether they both express existence too. What turns on this issue? Why not regard both views as equally acceptable precisifications of our ordinary notion of existence? I see no reason not to do so. One precisification stays closer to ordinary usage, restricting 'existence' to the first order. The other precisification expands ordinary usage to track the more general and fundamental underlying notion. Both precisifications are equally legitimate. Dispute about which is correct is no more substantive than dispute about whether uses of 'mass' prior to the discovery of special relativity express relativistic mass or proper mass. Prior usage didn't distinguish between two interpretations which we now see come apart. As a result, a semantic decision must now be made, with neither choice ruled out by earlier usage as incorrect. There is thus a perfectly legitimate sense in which all orders of existential quantification express existence. On this precisification of our ordinary notion of existence, second-order realism is indeed a form of realism.... (Jones, 2018, p. 816; cf. Jones, 2016, pp. 147-148)

Here Jones argues that there are two notions of existence which ontological debate has failed to distinguish. I am not convinced that this deals with the objection. In the case of 'mass', prior usage did indeed fail to distinguish between two interpretations (see Field, 1973)—but is the same true of 'exist'? It would seem not. There just isn't a way of reading the question 'Does redness exist?' such that a second-order claim, such as ' $\exists Y(Y \mathrm{~h} \wedge \forall z(Y z \rightarrow \mathrm{R} z))$ ', answers it. I doubt that presenting ontologists with Jones's interpretations would reveal that they had failed to distinguish the first-order notion of existence from the "more general and fundamental' underlying notion. It seems more likely that ontologists used first-order formulations because that is what they intended. This impression is confirmed by the important role that the first-order existential quantifier plays in Quinean and post-Quinean ontology (for instance, in van Inwagen's work). The following passages are illustrations. In each of them, a philosopher who is certainly aware of the relevant distinctions classifies ontological questions as first-order:

The lesson to be drawn from the foregoing reflections on plurals and second-order logic is that neither the use of plurals nor the employment of second-order logic commits us to the existence of extra items beyond those to which we are already committed.... Ontological commitment is carried by our first-order quantifiers.... (Boolos, 1984, p. 449, italics in the original)

By definition, ontology concerns what there is. Claims of the form 'There is a $G^{\prime}$ are naturally paraphrased by first-order sentences of the form $\exists x G x$. The quantification in 'There is a $G$ ' is not into predicate position.... The 
content of the ontological commitment is true if there is a $\mathrm{G}$ and false otherwise. Its truth value depends on how the mostly non-linguistic world is, as characterized in first-order terms. ... If higher-order quantifiers are neither reducible to first-order terms nor metalinguistic, then a higher-order commitment of the form $\exists X \Phi X$ is typically neither ontological nor ideological. ... [N]ot all metaphysical commitment is ontological commitment. (Williamson, 2013, p. 260)

A further consideration pointing in the same direction is that instances of Exist $2 *$ are logical truths. They follow by standard logical manoeuvres from the instances of.

(4) $\forall x(\mathrm{~F} x \rightarrow(\mathrm{F} x \wedge \forall z(\mathrm{~F} z \rightarrow \mathrm{F} z)))$,

which are logical truths. ((4) is of course (3) minus the boxes.) Many philosophers believe that the existence of things cannot be established by logic alone (e.g. Field, 1989, pp. 5, 167-170). Whether or not that belief is true, the fact they hold it bears on the interpretation of ontological questions: it counts against interpretations of those questions that make them answerable by logical truths. On Jones's view, the answer to 'Are there properties?' can easily be reached from no premisses by basic deductive reasoning. Anyone holding such a view requires a strong argument to establish that the alleged answer really does answer the question. In Jones's case, it is fairly easy to establish second-order realism*-but much harder to relate second-order realism* to the existing debate over properties. I have been suggesting that Jones changes the subject and so does not resolve the debate.

A possible fall-back position for Jones would be to maintain that the subject ought to be changed. (There is a hint of this at Jones, 2016, p. 148.) He could concede that ontologists currently give special significance to first-order existence claims but argue that they ought to think of these claims as no more important than secondorder existence claims, or existence claims of even higher orders. A focus on firstorder existence would be diagnosed as a type of metaphysical myopia hiding the full richness of the existential aspects of reality. Traditional ontological questions are bad questions because their first-order character gives them a narrowness at odds with the metaphysical aspiration to be entirely general. If Jones takes this position, then he is engaged in 'conceptual ethics' (or 'conceptual engineering') - that is, the study of 'how one ought (or would do well) to think and talk' (Burgess \& Plunkett, 2013, p. 1091).

There are several ways to argue that a question is a bad one. You can show that it makes no sense. You can show that, although the question can be presumed to make sense, our epistemic limitations will prevent us from ever finding out the answer. On either of those approaches, the question deserves to be dropped. Another approach is to argue that the question is bad because it uses concepts (or linguistic expressions) that are sub-optimal for the purposes at hand. The fall-back position I am exploring here is an approach of this sort. It does not imply that the question makes no sense, or that we will never be in a position to answer it; the claim is rather that the answer to the question would be of little theoretical significance. 
Any claim that a question is bad because it uses sub-optimal concepts invites this response:

I agree that the question doesn't use the optimal concepts available, and I agree that there is a better question in the vicinity which uses concepts better suited to our purpose and whose answer will be of greater significance. Still, you concede that the original question makes sense, and that we might be able to answer it. Since I've got interested in that question, I'd still like to know-just for the record-what the answer to it is.

The fall-back position here envisaged for Jones invites just this response. Even if it is right that it would be theoretically rewarding to move away from first-order questions, there remains the matter of what the answers are to the (traditional, not so good) first-order questions.

There is a further threat to Jones's position here. Suppose that one of the usual arguments for the existence of properties succeeds. As those arguments are framed in first-order terms (see Sect. 3), their success would establish first-order realism*. But Jones's efforts to dissolve the question of whether properties have a location rest on the falsity of first-order realism*. If first-order realism* is true, then there are properties and we can refer to them using singular terms. For example, if electronhood is one of the properties, then we can use a regular first-order location predicate to ask whether electronhood is located at Sydney, and so the location question is not dissolved after all. Much of the significance of Jones's project rests on the falsity of a particular first-order ontological thesis, and so it is not open to him to dismiss firstorder ontological claims as unimportant.

\subsection{Jones's commitment to plural realism}

In this section I pose another criticism of Jones's position. In short (a) plural expressions are ontologically innocent, but (b) Jones is committed to saying that they are not. Let me explain (a) and (b) in turn.

The ontological innocence of plurals is the thesis that plural terms and quantifiers provide a useful way of talking about the very same things we talk about when using singular expressions: there is no distinctive level of ontology corresponding to plurals. If plurals are ontologically innocent, the plural term 'Melbourne and Sydney' is a device for talking about the very same things we talk about using the singular terms 'Melbourne' and 'Sydney'. It 'introduces no new ontological commitments to sets or any other kind of "set-like" entities over and above' Melbourne and Sydney (Linnebo, 2017: section 5; Linnebo does not endorse this claim himself). And if plurals are ontologically innocent in this way, plural quantifiers-for instance, 'Some things', or 'Some Australian cities' - do not introduce such commitments either. (Boolos, 1984 is a classic statement of this view.)

I take the ontological innocence of plurals to be extremely plausible. I am aware that it is a matter of debate, but, for present purposes, I will assume it to be true.

Jones ought to deny the innocence of plurals. Consider the claim that for a certain range of substitutions for ' $\Phi$ ', the instances of this schema are true: 


$$
\forall x(\Phi x \rightarrow \exists x x \forall y(y<x x \leftrightarrow \Phi y)),
$$

where '<' symbolizes 'is among' (or 'is one of'). In parallel to his other higherorder realism about properties, Jones ought to call this claim 'higher-order realism about plurals'. For Jones, establishing this claim would be enough to show that plural quantification is not ontologically innocent.

As it happens, it is easy to establish it. Start with the comprehension schema for plurals:

$$
\text { Comp: } \exists x \phi(x) \rightarrow \exists x x \forall y(y<x x \leftrightarrow \phi(y))
$$

where ' $\phi$ ' holds a place for an open sentence that does not contain ' $x x$ ' free. Instances of Comp are commonly taken as axiomatic in plural logic, or at any rate as logical truths (Yi, 2006, p. 326, axiom 13; Oliver \& Smiley, 2013, pp. 242-243). As Jones might put it, they are 'uncontroversially true'. But on the basis of this schema, it is trivial to derive higher-order realism about plurals. Jones is thereby committed to higher-order realism about plurals, and to denying the extremely plausible claim that plurals are ontologically innocent.

There is a parallel argument in Florio and Linnebo (2016). Florio and Linnebo are tentative but come close to biting the bullet:

The semantics [for plural expressions] developed in a plural metalanguage cuts both ways. Both parties to the debate can agree that if the use of the plural quantifiers in the metalanguage is innocent, then so is their use in the object language. One party will assert the antecedent, while the other will deny the consequent. ... If [the notion of ontological commitment] is understood in the narrow sense (i.e. as concerned exclusively with the existence of objects), and if an object is understood as the value of a singular firstorder variable, then the plurality-based semantics does indeed show that plural logic is ontologically innocent. ... However, there is a broad notion of ontological commitment. According to this notion, ontological commitment is tied to the presence of existential quantifiers of any logical category in a sentence's truth conditions. If this notion is operative, then even the plurality-based semantics shows that plural locutions incur additional ontological commitments. ... It may be objected to the broad notion of commitment that the commitments associated with plural and higher-order quantifiers is not a form of ontological commitment but perhaps, following Quine, of ideological commitment. We see little point in quarreling over terminology. (Florio \& Linnebo, 2016, pp. 575, 577; see also Linnebo, 2017: section 5.4; and Rayo, 2007, pp. 435-436)

The suggestion here is that whether plural resources invoke new ontological commitments is a terminological choice rather than a more substantive issue.

Our choice of terminology is arbitrary, but there is an important non-terminological matter in the vicinity: do claims made in terms of the broad notion of commitment answer traditional ontological questions? Or does broad ontological commitment raise a new suite of questions, distinct from the traditional questions of whether there are numbers, properties, tables, etc.? Does the term 'commitment' 
mark a genuine connection with these questions? Jones's work raises just the same issues.

\section{Arguments for the existence of properties}

\subsection{The "one over many" argument}

Having put forward some criticisms of Jones's position, I now offer my own view. I think that adding sui generis second-order quantification and other higher-order resources to our ideology does not resolve the debate over the existence of properties, but instead weakens the case for the existence of properties, by defeating three of the main arguments for the existence of properties. In the remainder of the paper, I will seek to establish this claim. There is a trade-off between ontology and ideology (see Yablo, 2000, p. 207); since the higher-order metaphysician expands their ideological resources, it will not be surprising if they can make do with a slimmer ontology.

Some might suggest that anyone who adds higher-order resources to their ideology ought to claim that natural language expressions such as 'exist', which are not accompanied by careful typing, have more than one reading - in which case the sentence 'Properties exist' has a first-order reading and higher-order readings as well. Rather than evaluating this suggestion, let me simply say that if it proves to be correct, then I stipulate that my argument here is about whether properties exist on the first-order reading of 'exist'. For reasons I gave in Sect. 2.2, I take that to be the subject of the traditional ontological debate over the existence of properties.

Let me begin by discussing the "one over many" argument. This ancient argument is best known today in D. M. Armstrong's version. I will now give a brief review of Armstrong's argument and the ensuing debate, before explaining how the introduction of sui generis second-order quantification undermines the argument.

According to Armstrong (1980, p. 102), 'We are continually talking about different things having the same property or quality, being of the same sort or kind, being of the same nature, and so on'. Some of these claims state Moorean facts-facts which 'constitute the compulsory questions in the philosophical examination paper' (1980, p. 102). Armstrong maintains that to give an account of these facts, we need to postulate properties.

For Armstrong's opponent Michael Devitt, it seems easy to give an account of such facts without postulating properties. Take, for instance, a Moorean fact expressed by a sentence of the form:

$a$ and $b$ have the same property (are of the same type), $F$-ness.

Inspired by Quine, Devitt claims that this can be analysed into:

$a$ and $b$ are both $F$.

-which in turn can be analysed into two facts:

$a$ is $F$. 


\section{$b$ is $F$.}

Devitt (1980, p. 95) claims that since these facts can obtain without there being any properties, we have therefore accounted for the Moorean fact without invoking properties, and so Armstrong's argument fails.

Lewis (1983, p. 355) challenges Devitt to deal with cases where there shared type is not given explicitly, for instance, the fact that.

$a$ and $b$ have some common property (are somehow of the same type).

Devitt's method of analysis does not work unless the type in question is specified. So-Lewis argues-Devitt has not dealt with this part of Armstrong's argument.

Once we add second-order quantification to our ideology, we can analyse the fact that $a$ and $b$ have some common property as the fact that:

(5) $\exists X(X a \wedge X b)$.

If this quantification were given an objectual reading in terms of properties, it would mean that there is a property had both by $a$ and $b$, which would obviously be of no use for resisting Armstrong's argument. If instead it were read objectually in terms of sets, it would mean that there is a set containing both $a$ and $b$; but for any two things, there is a set that contains them both, and so this reading is too weak to capture the idea that $a$ and $b$ are genuinely of the same nature (Lewis, 1983, p. 346). If the quantification were read substitutionally, (5) would mean 'There is a linguistic expression such that substituting it into both blanks in "_ $a$ $\wedge_{-} b$ " yields a truth'. That might be an adequate analysis in cases where there is a predicate capturing the specific way for things to be that $a$ and $b$ have in common. But in cases where there is no such predicate, (5) is not true, and so there is no such thing as the fact that $\exists X(X a \wedge X b)$. The analysis will then be inadequate. Neither objectual nor substitutional readings are any help.

This is where a higher-order perspective makes a difference, because it provides a further reading of (5). On this reading, the quantification it contains is genuinely higher-order, irreducible to first-order quantification. So interpreted, (5) is a generalization of ' $F a \wedge F b$ ', one that retains the reference to the individuals $a$ and $b$ but no longer singles out a specific respect in which they are alike. In this way, sui generis second-order quantification provides a way to answer Lewis's challenge. Van Cleve is therefore right to say that'If there were such a form of quantification, we could use it to get around the objection to Devitt' (1994, p. 588).

How might the realist respond? They might claim that the sort of quantification I am discussing is unintelligible, so there is no such reading of (5). As I said at the outset, I am assuming that sui generis second-order quantification is intelligible, so I set this response aside.

Another response is to concede that there is the higher-order reading of (5), but assert that it does not undermine the case for realism, for on this reading (5) implies the existence of properties.

It would not be successful for the realist just to make this assertion. They need to establish that: 
If $\exists X(X a \wedge X b)$ then there are properties.

Presumably the realist will hold that there is nothing special about (5): they will claim that every sui generis second-order existential generalization implies the existence of properties, and endorse every instance of the following schema:

If $\exists X\left(\_\right)$then there are properties.

For insight into how this claim might be established, consider what I will call Prior's Principle:

An existential generalization implies the existence of $X$ s only if each instance of the generalization implies the existence of $X \mathrm{~s}$.

For instance, ' $\exists x F x$ ' implies the existence of $G$ s only if all sentences of the form ' $\mathrm{Fa}$ ' imply the existence of $\mathrm{Gs}$. For an existential generalization to commit us to kinds of entities to which its instances do not commit us would have 'an almost magical air about it', in Prior's phrase (1971, p. 43). The principle follows directly from the transitivity of implication: each instance implies the generalization and so by transitivity each instance implies everything that the generalization implies. (I take Prior, 1971, p. 43 to hint at this argument. Rayo \& Yablo, 2001, p. 81 make a similar argument using the concept of trivial entailment. Wright, 2007 offers a principle called 'Neutrality' which echoes Prior's Principle, but does not relate it to Prior's work.)

It follows from Prior's Principle that a sui generis second-order existential generalization implies the existence of properties only if each of its instances does. So the realist who maintains that (5) implies the instance of properties must also maintain that ' $\mathrm{Fa}$ ' does. That shows us that this response does not take us anywhere new. There was already a debate concerning whether subject-predicate sentences imply the existence of properties: the current response returns us to that debate. The "one over many" was meant to be an alternative to that line of argument. Moreover, the view that ' $\mathrm{Fa}$ ' implies the existence of the property of being $F$ is well known to be hopeless, since it leads to the property version of Russell's paradox: "Electronhood does not exemplify itself" is true but it cannot imply the existence of the property of being non-self-exemplifying, on pain of contradiction (see Künne, 2006, pp. 281-283).

I therefore take it that the realist response of arguing that (5) implies the existence of properties is unpromising. (See also Rayo \& Yablo, 2001, pp. 81-82 for arguments that (5) lacks that implication.)

A different response focuses on ideology. I have suggested analysing the fact that $a$ and $b$ have some common property as the fact that $\exists X(X a \wedge X b)$, a suggestion to which the concept of sui generis second order quantification is indispensable. By invoking that concept I complicate my theory, since I complicate its ideology. So even if that enables me to make an ontological saving (by resisting realism about properties), it is not clear that the theory I end up with is better overall.

The higher-order metaphysician can refute this objection if they can show that the ontological benefit exceeds the ideological cost. Joseph Melia's distinction between different sorts of simplicity provides a way to do so (2000, pp. 472-475, 2015, pp. 
181-187). Melia draws a distinction between how simple a theory is to formulate, and how simple the world is that the theory depicts. For example, he argues that if we add plural quantification to our ideology, we thereby reduce the simplicity of formulation of our theory. But he also argues that adding plural quantification does not reduce the simplicity of the world depicted by the theory:

it is not plausible to take the appearance of unanalysed or primitive plural quantification in our theories as representing some new, unreduced and irreducibly plural features of reality. A description of reality in first order terms ... is still a complete description of reality. Even though the description contained no plural quantifications, nothing would be left out, no feature of reality omitted. The plural quantifiers, then, are conceptual primitives ...[b]ut ... [t]hey are metaphysically neutral. (2015, pp. 181-182)

When Melia speaks here of 'first-order terms' he is best interpreted as speaking about quantification: it is less plausible to maintain that we can give a complete description of reality without using plural terms and plural predicates (see Oliver \& Smiley, 2013, pp. 7-12, 33-72 for relevant discussion). Anyone who is sympathetic to the ontological innocence of plurals (Sect. 2.3) is likely to be sympathetic to what Melia says here.

Melia puts this distinction to work when he claims that the simplicity of the world depicted is what should matter to theory choice. According to Melia, simplicity of formulation is not a genuine theoretical virtue; what matters is the simplicity we attribute to reality, not the number of primitive predicates or concepts we need to make that attribution (see also Sider, 2011, p. 14).

I accept Melia's claims. Their bearing on the higher-order response to the "one over many" is clear. By employing sui generis second-order quantification, we reduce our theory's conceptual simplicity, but we do not reduce the simplicity of the world the theory depicts. Just like plural quantifiers, sui generis second-order quantifiers are ways for describing the same entities we talk about using singular reference and predication; they just allow us to do so with greater generality. The greater generality of quantified statements is useful to the theorist when the more specific claims which imply them are unavailable. As Melia (1995) argues, this unavailability can be the result of epistemic or linguistic limitations. Sui generis second-order quantifiers therefore do not reduce the simplicity of the world the theory depicts; because conceptual simplicity is not a theoretical virtue, this extra ideology comes at zero cost. So the cost does not outweigh the ontological benefit.

It is natural to be suspicious of Melia's position, because it seems to have the absurd consequence that ideological complexity does not matter to theory choice at all. But that would be a misunderstanding. Although second-order and plural quantifiers come for free, not all new ideology is like that. Suppose we introduce a new primitive predicate ' $K$ '. As soon as we include ' $\exists x K x$ ' in our theory, or anything that implies it, we gain an ontological commitment to $K$ s, and so we increase the ontological complexity of the world the theory depicts (see Pickel \& Mantegani, 2012, pp. 8-10). On Melia's position, we thereby increase our theoretical costs in this respect. Of course, this increase may well be outweighed by an increase in theoretical benefit along other dimensions. The point is that in this 
case an ideological addition brings a theoretical cost-but this increase in theoretical cost comes indirectly, through an increase in ontological complexity. For Melia, as I interpret him, ideological simplicity is not itself a theoretical virtue, but it still makes a difference to theory choice, since the ideological simplicity of a theory sometimes makes a difference to how much of the genuine theoretical virtues a theory has. Melia's methodological views are defensible and allow us to show that the sort of quantification I have invoked comes with no ideological cost.

In this section, I have shown that allowing (5) to receive a genuinely higher-order reading is enough to defeat Armstrong's "one over many" argument for properties; and I have defended this response from some objections. Before I turn to another argument for the existence of properties, I will mention a further way in which a higher-order perspective makes a difference to Armstrong's argument.

As we have seen, the strongest version of the argument starts from those Moorean facts of sameness of type which can be stated without specifying which type is shared, for instance, the fact that $a$ and $b$ have some common property. For Armstrong, we express these facts by speaking of properties, or using other expressions that plausibly refer to properties if they refer at all. (To repeat a sentence I quoted above: 'We are continually talking about different things having the same property or quality, being of the same sort or kind, being of the same nature, and so on' (Armstrong, 1980, p. 102).) From a first-order perspective, these are the only ways to make claims of sameness of type: the sentence ' $a$ and $b$ are both $F$ ' is not general enough. So the very facts to be accounted for are ones which are expressed in terms of the entities whose existence is in question.

That seems unsatisfactory. It is not that it makes the argument question-begging: Armstrong admits the epistemic possibility that these facts can obtain even if there are no such things as properties, and proceeds to try and rule it out, so he is innocent of begging the question. Rather, the problem is that his opponent can argue that Armstrong has misidentified the facts to be accounted for. Once we have genuinely higher-order quantification available, we can use it to state facts of sameness of type which make no mention of properties, qualities, sorts, kinds, or natures, and do not obviously imply their existence. These claims have the form of (5). Higher-order quantification therefore presents Armstrong with a new challenge: to show that the Moorean facts of sameness of type are those he points to, and not those which instances of (5) express.

This is not merely a sceptical doubt. We have a positive reason to think that these different facts might have been confused. To make claims of sameness of type, we often find ourselves speaking of properties, qualities, and so on. We can also use 'There is something $a$ and $b$ both are', but the presence of the copula 'are' means that this does not contain quantification into predicate position (Künne, 2006, pp. 273-4). No instance of (5) has a natural English synonym, and (so far as I know) other natural languages are no better off. That implies that the challenge invites us to consider something which we do not ordinarily have the means to express. Now that we have the means, the identity of the Moorean fact needs to be reconsidered. Precisely because we did not have a way of stating it, we may have confused the genuinely Moorean fact with another fact which we did have the means to state. In 
other words, talk of properties may arise here merely as a result of the impoverished expressive capacity of natural language.

If the defender of Armstrong cannot meet this challenge, then the debate returns to the question of what entities must exist in order for the facts stated by instances of (5) to obtain. That question leads us away from the "one over many" and back to the debate over the ontological implications of subject-predicate sentences, as I argued earlier in this section.

\subsection{The reference argument and the quantification argument}

Another important argument for realism about properties is what Edwards (2014, p. 4) terms the reference argument. It easy to state: since there are true sentences which apparently refer to properties, properties exist. The following sentences, taken from Lewis (1983, p. 348), are examples:

(6) Red is a colour.

(7) Humility is a virtue.

It seems that these sentences are true only if there are things for 'red' and 'humility' to refer to. Since they are true, those things exist. And it is not plausible to take them to be anything other than properties. So properties exist.

To resist the reference argument, there are two broad strategies. One may claim that the sentences in question can be true even if there are no properties. Call this the paraphrase strategy. Or one can claim that the sentences are not true. Call this the error-theoretic strategy.

According to the paraphrase strategy, while (6) and (7) might appear to be descriptions of properties, they are not. Anyone who makes this claim faces the question of what (6) and (7) really mean, and a natural way to respond is to give paraphrases of these sentences, to clarify their meaning-hence the term "paraphrase strategy'. These paraphrases are not intended as replacements for the sentences, but as elucidations of what they meant all along.

A familiar problem for paraphrase strategies in metaphysics is that the paraphraser's claims about the meanings of sentences are often very implausible (see e.g. Nolan, 2010, p. 239 on van Inwagen and Richard, 2006, p. 174 on Horgan and Potrč). The same problem arises here. As used in (6) and (7), 'red' and 'humility' behave syntactically like singular terms and seem to have the function of picking out properties. It is very implausible that (6) and (7) could be true unless there were such things as redness and humility. Perhaps some ingenious argument could be found to show that appearances are deceptive here, but I do not know of one, and therefore I will set the paraphrase strategy aside. (Jago argues that using second-order quantification does not help to avoid commitment to properties because it takes from the anti-realist the resources to deny that properties exist (2018, p. 63). He has in mind the view that all talk about properties is to be interpreted in second-order terms, so this objection is relevant only to the paraphrase strategy; it should not worry an error theorist.) 
The error-theoretic strategy is to maintain that (6) and (7) are not true; and, more generally, to maintain that there is no true sentence that requires the existence of a property for its truth. Now many sentences that seem to make reference to properties also seem to express widely held beliefs: (6) and (7) are examples. The errortheoretic strategy implies that these widely held beliefs are not true, and so do not constitute knowledge. The leading objection to error theory is that it is uncharitable: it would not be plausible for the error theorist to treat these beliefs like astrological beliefs and reject them altogether. To respond to this objection, the error theorist must find some positive epistemic status for these beliefs about properties (for helpful discussion, see Kovacs, 2021). It is here that higher-order resources make a difference, as I will now explain.

There are many ways to offer these beliefs a positive epistemic status. One might claim that we confuse them with beliefs that do constitute knowledge (see Marksoian, 2004, pp. 69-73 for a version of this move in defence of presentism). One might claim that we believe them because they help us to communicate truths (see Jones, 2019, pp. 175-176 for a version of this move in connection with proposition-talk). Or one might claim that the beliefs, while untrue, are quasi-true, where a belief B is quasi-true iff there is some true proposition $\mathrm{C}$ such that, had there been properties, $\mathrm{C}$ would have been true and it would have metaphysically necessitated the truth of B (Sider, 1999, p. 340); this captures the idea that B is true apart from presupposing the existence of properties. Since ordinary empirical evidence does not settle whether properties exist, it does not discriminate between truth and quasitruth, and so we can be forgiven for believing things which are only quasi-true (see Sider, 1999 for a development of this strategy in defence of presentism).

I do not need to choose between these strategies for my purposes here. Whichever strategy the error theorist uses to reply to the reference argument, higher-order resources help. To see this, note that each strategy gives a belief a positive epistemic status by associating it with a truth: the belief we confuse it with (on the first strategy), the belief it helps us communicate (on the second strategy), or the belief that stands as $\mathrm{C}$ to $\mathrm{B}$ (on the third strategy). Call these the underlying truths.

How should the error theorist go about finding underlying truths for the beliefs expressed by (6) and (7), and for other apparently true beliefs that imply the existence of properties? The debate over the paraphrase strategy already supplies some candidates. Even though it is widely agreed that these fail to be synonymous with the sentences they are supposed to paraphrase, it is worth checking whether they can play the role of underlying truths instead. For instance, we should consider whether the truth underlying (6) might be:

(6*) Everything red is coloured.

or

$\left(6^{* *}\right)$ Necessarily, everything red is coloured.

The problem is that the proposal over-generates. If $\left(6^{*}\right)$ or $\left(6^{* *}\right)$ is the truth underlying (6), then we should think that.

$\left(8^{*}\right)$ Everything red is shaped. 
or

(8**) Necessarily, everything red is shaped.

is the truth underlying

(8) Red is a shape.

But any belief in (8) is just mistaken, whether or not there are properties. It does not deserve a positive epistemic status. So it seems that the alleged paraphrases $\left(6^{*}\right)$ and $\left(6^{* *}\right)$ are of no use to error theorists. (This argument is adapted from Jackson's (1977, p. 427) argument against the paraphrase strategy.)

Higher-order resources come to the rescue. What is required here is not a special type of quantification but a special type of predication. The error theorist needs predicates which when applied to a first-order predicate yield a complete sentence. I will print these in bold type and call them 'second-order' predicates (confusingly, they are also sometimes called 'third-order' predicates). With these resources at hand, we can easily find underlying truths for (6) and (7):

(6') CR.

(7') $\mathrm{VH}$.

Here ' $R$ ' and ' $H$ ' are first-order predicates meaning 'is red' and 'is humble' respectively. ' $\mathbf{C}$ ' and ' $\mathbf{V}$ ' are second-order predicates. ' $\mathbf{V}$ ' stands to 'is virtuous' just as 'is virtuous' stands to 'virtuousness'; 'C' stands to 'is coloured' just as 'is coloured' stands to 'being coloured'. The error theorist can offer the beliefs expressed by (6) and (7) a positive epistemic status by associating them with the truths $\left(6^{\prime}\right)$ and $\left(7^{\prime}\right)$ respectively. Higher-order resources help the error theorist to give many beliefs which imply the existence of properties the positive epistemic status they deserve, thereby enabling the error theorist to overcome the reference argument.

A related argument for realism about properties appeals to apparent quantification over properties, rather than apparent reference:

(9) Acquired characteristics are not inherited.

(10) He has the same virtues as his father.

(These are taken from Armstrong, 1980, pp. 105, 106.) Edwards (2014, p. 6) terms this the quantification argument. Again, the argument is that these sentences are true, and that their truth implies the existence of properties. It is easy to see that the same strategy is just as promising here, provided that sui generis second-order quantification is available. The error theorist can associate the beliefs expressed by (9) and (10) with.

$\left(9^{\prime}\right) \forall X(\mathbf{A} X \rightarrow \neg \mathbf{I} X)$.

and

$\left(10^{\prime}\right) \forall X((\mathbf{V} X \wedge X \mathrm{~b}) \rightarrow X \mathrm{a})$. 
respectively, where ' $X$ ' is a second-order variable, ' $a$ ' and ' $b$ ' are names for the person in question and his father respectively, and ' $\mathbf{A}$ ', ' $\mathbf{I}$ ', and ' $\mathbf{V}$ ' are appropriate second-order predicates.

Here and in the response to the reference argument, we introduce new ideology, and so we must again face the question of whether this is too high a price to pay. But introducing the new ideology not only enables us to avoid positing properties, but also brings an ideological saving: since claims such as (6) and (7) do not appear in our theory, we no longer need names for properties. So the introduction of higherorder predicates seems to bring overall theoretical benefit.

One criticism is that $\left(6^{\prime}\right)$ and $\left(7^{\prime}\right)$ do not mention any entities, and do not seem to depend on how things are with any entities; their truth 'floats free' of reality in an objectionable way. There are two ways of developing this criticism.

The first way is to claim that the philosopher who endorses $\left(6^{\prime}\right)$ and $\left(7^{\prime}\right)$ but denies the existence of properties posits truths without truthmakers. The only entities that could make $\left(6^{\prime}\right)$ and $\left(7^{\prime}\right)$ true are entities which exist only if properties dofor instance, the fact that humility has the higher-order property of being a virtue property. If there are no properties, there $\left(6^{\prime}\right)$ and $\left(7^{\prime}\right)$ are truths without truthmakers, and that offends against the tenets of truthmaker theory.

Understood in this way, the criticism relies on the claim that for every truth there is some entity that makes it true. But that claim is no platitude; and the arguments that are meant to establish it do not suffice to do so, as the critics of truthmaker theory have shown (e.g. Dodd, 2002; Liggins, 2008; Williamson, 1999).

There is a deeper point here. Appealing to truthmaker theory to attack the higherorder response to the reference argument is likely to beg the question. That is because the central claim of truthmaker theory is one which higher-order metaphysicians will probably reject: 'Truthmaker theory says the brute truths are all of a kind: they are the truths that concern only what there is' (Cameron, 2008, p. 125). For the truthmaker theorist, we can specify a world up to uniqueness just by listing what things are in it. Higher-order metaphysicians are likely to go much further and claim that there are aspects of reality that can only be captured by higher-order resources, such as those expressed by $\left(6^{\prime}\right)$ and $\left(7^{\prime}\right)$. Absent further argument, we should expect that at least some brute truths will record such aspects of reality. Higher-order metaphysicians will therefore reject the central tenet of truthmaker theory. So appeal to truthmaker theory leads to a wider and difficult debate about which sorts of truths are brute.

An alternative way of developing the criticism of the higher-order response to the argument from reference appeals not to truthmaker theory but to the weaker claim that what is true depends on what there is and how it is. The suggestion is that we need properties in our ontology in order to explain why $\left(6^{\prime}\right)$ and $\left(7^{\prime}\right)$ are true. Developed in this way, the criticism leads back to just the same debate over which truths are brute. (The idea that truth depends on what there is and how it is represents an intermediate position between the truthmaker theorist's claim that the brute truths concern which things there are and the higher-order metaphysician's claim that there are brute truths that require higher-order resources for their expression.) As Cameron points out, that truthmaker theory posits relatively few brute truths speaks in its favour, but that benefit is to be weighed against the ontological costs of belief in 
truthmakers (see Cameron, 2008, pp. 125-127). Perhaps another theory of which truths are brute will turn out to have the best balance of benefits over costs. For this reason, both versions of the criticism are inconclusive.

\section{Conclusion}

I have re-examined the debate over the metaphysics of properties from a higherorder perspective. Jones argues that adding sui generis second-order quantification to our ideology is enough to establish the existence of properties. In Sect. 2, I explained why I am not persuaded by his case. I argued that Jones does not settle the question of whether there are properties because-like other ontological questions-it is first-order. And in Sect. 3 I considered three of the main arguments for properties' existence, concluding that sui generis second-order quantification defeats the "one over many" argument and that, coupled with second-order predication, it also defeats the reference and quantification arguments. If the other arguments for the existence of properties are no better, then a higher-order metaphysician should not believe in properties.

Acknowledgements I would like to thank Nick Jones, Matti Eklund, Lukas Skiba, and Jeroen Smid. Thanks also to participants in the Deflationism in Metaphysics conference, Vienna, December 2017, and the Language and the World conference, Graz, August 2019.

Open Access This article is licensed under a Creative Commons Attribution 4.0 International License, which permits use, sharing, adaptation, distribution and reproduction in any medium or format, as long as you give appropriate credit to the original author(s) and the source, provide a link to the Creative Commons licence, and indicate if changes were made. The images or other third party material in this article are included in the article's Creative Commons licence, unless indicated otherwise in a credit line to the material. If material is not included in the article's Creative Commons licence and your intended use is not permitted by statutory regulation or exceeds the permitted use, you will need to obtain permission directly from the copyright holder. To view a copy of this licence, visit http://creativecommons.org/licen ses/by/4.0/.

\section{References}

Armstrong, D. M. (1980). Against 'Ostrich' Nominalism: A reply to Michael Devitt. Pacific Philosophical Quarterly, 61, 440-449. Page references are to the reprint in D. H. Mellor \& A. Oliver (Eds.), Properties (pp. 101-111). Oxford University Press (1997).

Boolos, G. (1984). To be is to be a value of a variable (or to be some values of some variables). Journal of Philosophy, 81, 430-449.

Burgess, A., \& Plunkett, D. (2013). Conceptual ethics I. Philosophy Compass, 8, 1091-1101.

Button, T. (2020). Deflationary metaphysics and ordinary language. Synthese, 197, 33-57.

Cameron, R. (2008). Truthmakers, realism and ontology. Royal Institute of Philosophy Supplement, 62, $107-128$.

Cameron, R. (2019). Truthmaking, second-order quantification, and ontological commitment. Analytic Philosophy, 60, 336-360.

Devitt, M. (1980). 'Ostrich Nominalism' or 'Mirage Realism'? Pacific Philosophical Quarterly, 61, 433439. Page references are to the reprint in D. H. Mellor \& A. Oliver (Eds.), Properties (pp. 93-101). Oxford University Press (1997).

Dodd, J. (2002). Is truth supervenient on being? Proceedings of the Aristotelian Society, 102, 69-85. 
Edwards, D. (2014). Properties. Polity.

Eklund, M. (2016). Review of Amie L. Thomasson's Ontology made easy. Notre Dame Philosophical Reviews. https://ndpr.nd.edu/news/ontology-made-easy/.

Field, H. (1973). Theory change and the indeterminacy of reference. Journal of Philosophy, 70, 462-481.

Field, H. (1989). Realism, mathematics and modality. Blackwell.

Florio, S., \& Linnebo, Ø. (2016). On the innocence and determinacy of plural quantification. Nô̂s, 50, $565-658$.

Hale, B. (2013). Necessary beings: An essay on ontology, modality, and the relations between them. Oxford University Press.

Jackson, F. (1977). Statements about universals. Mind, 86, 427-429.

Jago, M. (2018). What truth is. Oxford University Press.

Jones, N. K. (2016). A higher-order solution to the problem of the concept horse. Ergo, 3, 132-166.

Jones, N. K. (2018). Nominalist realism. Nô̂s, 52, 808-835.

Jones, N. K. (2019). Propositions and cognitive relations. Proceedings of the Aristotelian Society, 119, $157-178$.

Kovacs, D. M. (2021). How to be an uncompromising revisionary ontologist. Synthese, 198, 2129-2152.

Krämer, S. (2014). On what there is for things to be: Ontological commitment and second-order quantification. Frankfurt: Klostermann.

Künne, W. (2006). Properties in abundance. In P. F. Strawson \& A. Chakrabarti (Eds.), Universals, concepts, and qualities: New essays on the meaning of predicates (pp. 249-300). Aldershot: Ashgate.

Lewis, D. (1983). New work for a theory of universals. Australasian Journal of Philosophy, 61, 343-377.

Liggins, D. (2008). Truthmakers and the groundedness of truth. Proceedings of the Aristotelian Society, $108,177-196$.

Linnebo, Ø. (2017). Plural quantification. In E. N. Zalta (Ed.), Stanford encylopedia of philosophy (Summer 2017 Edition). https://plato.stanford.edu/archives/sum2017/entries/plural-quant/

Marksoian, N. (2004). A defense of presentism. Oxford Studies in Metaphysics, 1, 47-82.

Melia, J. (1995). On what there's not. Analysis, 55, 223-229.

Melia, J. (2000). Weaseling away the indispensability argument. Mind, 109, 455-480.

Melia, J. (2015). Nominalism, naturalism and natural properties. In G. Guigon \& G. Rodriguez-Pereyra (Eds.), Nominalism about properties: New essays (pp. 175-188). Routledge.

Nolan, D. (2010). Metaphysical language, ordinary language and Peter van Inwagen's Material Beings. Humana Mente, 13, 237-246.

Oliver, A., \& Smiley, T. (2013). Plural Logic. Oxford University Press.

Peacock, H. (2009). What's wrong with Ostrich Nominalism? Philosophical Papers, 38, 183-217.

Pickel, B., \& Mantegani, N. (2012). A Quinean critique of ostrich nominalism. Philosopher's Imprint, $12,1-21$.

Prior, A. N. (1971). Objects of thought. P. T. Geach \& A. J. P. Kenny (Eds.). Oxford: Clarendon Press.

Rayo, A. (2007). Ontological commitment. Philosophy Compass, 2(3), 428-444.

Rayo, A., \& Yablo, S. (2001). Nominalism through de-nominalization. Noûs, 35, 74-92.

Richard, M. (2006). Context, vagueness, and ontology. In P. Greenough \& M. P. Lynch (Eds.), Truth and realism (pp. 162-174). Clarendon Press.

Sider, T. (1999). Presentism and ontological commitment. Journal of Philosophy, 96, 325-347.

Sider, T. (2011). Writing the book of the world. Oxford University Press.

Skiba, L. (forthcoming). Higher-order metaphysics and the tropes versus universals dispute. Philosophical Studies.

Thomasson, A. L. (2015). Ontology made easy. Oxford University Press.

Van Cleve, J. (1994). Predication without universals? A fling with Ostrich Nominalism. Philosophy and Phenomenological Research, 54, 577-590.

Williams, C. J. F. (1976). What is truth? Cambridge University Press.

Williamson, T. (1999). Truthmakers and the converse Barcan formula. Dialectica, 53, 253-270.

Williamson, T. (2003). Everything. Philosophical Perspectives, 17, 415-465.

Williamson, T. (2013). Modal logic as metaphysics. Oxford University Press.

Wright, C. (2007). On quantifying into predicate position: steps towards a new(tralist) perspective. In M. Leng, A. Paseau, \& M. Potter (Eds.), Mathematical knowledge (pp. 150-174). Oxford University Press.

Yablo, S. (2000). Apriority and existence. In P. Boghossian \& C. Peacocke (Eds.), New essays on the a priori (pp. 197-228). Clarendon Press.

Yi, B. (2006). The logic and meaning of plurals: Part II. Journal of Philosophical Logic, 35, 239-288. 
Publisher's Note Springer Nature remains neutral with regard to jurisdictional claims in published maps and institutional affiliations. 